\title{
Configuración socio histórica de un actor social colectivo: Reflexiones y propuesta teórica en clave interdisciplinar
}

\author{
Celia Cristina Basconzuelo ${ }^{1}$ \\ Centro de Estudios y de Gestión en Redes Académicas/Universidad Nacional \\ de Río Cuarto, CONICET, Río Cuarto, Argentina
}

Resumen: El presente artículo reflexiona sobre la categoría de actor social colectivo (ASC) y propone algunas dimensiones de análisis para el estudio de su configuración socio histórica, mediante herramientas conceptuales interdisciplinares particularmente provistas por la historia, la teoría social y la geografía. El trabajo se halla estructurado en tres partes, en las cuales se postulan dimensiones de análisis y sus respectivos indicadores como resultado de una exploración crítica previa de conceptos vinculantes con la conformación de un ASC. Se proponen dimensiones situadas (experiencia de acción y territorio), dimensiones macro sociales (entorno histórico) y dimensiones transversales (identificación y temporalidad) que procuran dar respuesta a la pregunta por las instancias de conformación del sujeto histórico, su identidad y la trayectoria que describe por su participación social, al mismo tiempo que pueden contribuir a orientar investigaciones empíricas en el futuro. Así, entendemos que el concepto ASC define un sujeto histórico cuya construcción colectiva deviene de una trayectoria donde se fija una experiencia de acción común, situada y de visibilidad pública, donde se desarrolla una cierta identificación que lo posiciona en relación con un entorno sociohistórico y sobre el cual puede llegar a incidir. La metodología es cualitativa. Las fuentes son bibliográficas, por un lado, y por el otro se integran con los resultados de nuestras investigaciones previas y proyectos en curso.

Palabras clave: Actores; Sociales; Colectivos; Interdisciplinar.

Título: Configuração sócio-histórica de um ator social coletivo. Reflexões e proposta teórica em chave interdisciplinar

Resumo: Este trabalho reflete sobre a categoria de ator social coletivo e propõe dimensões de análise para sua abordagem a partir de uma perspectiva de análise relacional, utilizando conceitos interdisciplinares. $O$ artigo se interessa, em primeiro lugar, pelas matrizes teóricas que norteiam a compreensão do assunto e permitem seguir o curso historiográfico que ele cobra nas ciências sociais entre meados do século XX e o presente. Em seguida, três dimensões de análise, localizadas, macrossociais e transversais, são propostas para dar conta da configuração sócio-histórica de uma ASC. A pesquisa é qualitativa e baseia-se em uma abordagem bibliográfica, como nos resultados de nossas publicações e projetos em andamento. Assim, entendemos que a noção de ator social coletivo se refere a qualquer sujeito de pertencimento a um coletivo, localizado, cujo

\footnotetext{
${ }^{1}$ Doctora en Historia (Universidad Nacional de Cuyo). Magister en Partidos Políticos (Universidad Nacional de Córdoba). Profesora y Licenciada en Historia (Universidad Nacional de Río Cuarto). Lugar de trabajo: Universidad Nacional de Río Cuarto. https:// https://www.unrc.edu.ar/. Orcid: https://orcid.org/0000-00019005-7227.
}

E-mail: cbasconzuelo2003@yahoo.com.ar 
processo constitutivo faz parte de uma matriz organizacional e de identificação, enquanto a configuração das ações com as quais se identifica (mais ou menos contencioso, com maior ou menor incidência no contexto) e posiciona-o no espaço público

Palavras-chave: Atores; Sociais; Coletivos; Interdisciplinar.

Title: Socio-historical configuration of a collective social actor. Reflections and theoretical proposal in interdisciplinary key

Abstract: This work reflects on the category of collective social actor and proposes dimensions of analysis for its approach from a relational analysis perspective, using interdisciplinary concepts. The article is interested, in the first place, in the theoretical matrices that guide the understanding of the subject and allow to follow the historiographic course that it charges in the social sciences between the mid-twentieth century and the present. Then, three dimensions of analysis, located, macrosocial and transversal, are proposed to account for the socio-historical configuration of an ASC. The research is qualitative and is based on a bibliographic approach as in the results of our publications and ongoing projects. Thus we understand that the notion of collective social actor refers to any subject of belonging to a collective, located, whose constitutive process is part of an organizational and identification matrix, while the configuration of the actions with which it is identified (more or less contentious, with greater or lesser incidence in the context) positions and makes it visible in the public space.

Keywords: Actors; Social; Colletive; Interdisciplinar.

\section{Introducción}

El estudio de los actores sociales colectivos (en adelante ASC) se ha constituido en un campo consolidado en las ciencias sociales. Una infinita producción académica compuesta por obras bibliográficas, artículos científicos, compilaciones y tesis integra el acervo de antecedentes que actualmente permiten abordarlos. Teorías y estudios de caso proponen tipologías y, aunque con cierto déficit en la determinación de posibles subconjuntos ${ }^{2}$, nos aproximan a sus localizaciones, identidades, trayectorias y perfiles. Por otra parte, los tiempos actuales muestran a escala latinoamericana sobre todo, ASC organizados, movilizados, demandantes, empoderados, que se constituyen y deconstituyen poniendo de relieve que, más allá de las particularidades, ocupan y disputan un lugar en el entramado social.

El repertorio de su denominación prácticamente se reduce a la expresión "actor colectivo" (CROZIER Y ERHARD FRIEDBERG, 1977; TOURAINE, 1987; GARCÍA SÁNCHEZ, 2007); o bien "sujetos históricos colectivos"3 (IBAÑEZ, 19914; DUSSEL, 1999), aunque las

\footnotetext{
${ }^{2}$ Me refiero, por ejemplo, a los denominados movimientos socio territoriales, socio ambientales y feministas, donde los estudios de caso estarían mostrando la necesidad de avanzar en subtipologías. Véase ese amplio arco de ASC abordado, entre otros autores, por SVAMPA (2006).

${ }^{3}$ Cabe agregar que la revalorización del sujeto tuvo soporte teórico en la sociología, la sicología social y en la filosofía, al resaltar las dimensiones subjetivas de la acción humana y la intersubjetividad comunitaria. En la tesis de DUSSEL (1999), los Ilamados "sujetos sociales" o "sujetos históricos", son denominados "actores sociohistóricos", por cuanto los considera "una cierta sustantivación de las entidades u organizaciones
} 
perspectivas son tan diversas como las fuentes epistemológicas que las validan. La teoría social y la antropología social trazan horizontes de estudio que resultan luego de aplicación para otras disciplinas e inclusive se acuñan nuevos conceptos en atención también a I desenvolvimiento de nuevos conjuntos sociales. ${ }^{5}$

Así puede trazarse un derrotero a partir de aquellas teorías que, durante buena parte del siglo XX, consideraron preferentemente a las clases sociales como $\mathrm{ASC}^{6}$, hasta las últimas dos décadas de la centuria cuando los enfoques de Touraine y sus discípulos, Castells, Melucci, junto con los de Alberoni, Offe, entre otros, y los aportes de la escuela norteamericana (Olson, Tilly), produciendo un giro en la delimitación de nuevos colectivos. (TARRÉS, 1992)

Con el transcurrir del primer decenio del siglo XXI, los estudios macro $\mathrm{y}$ microanalíticos permiten contar con una radiografía cada vez más compleja de ASC a partir de las cuales se puede desagregar un arco bastante amplio, que permite distinguir entre otros, a las organizaciones sociales, movimientos sociales ${ }^{7}$, profesionales ${ }^{8}$, cooperativas $^{9}$, quienes comparten algunos rasgos similares y aspectos que marcan significativas diferencias.

Sin embargo, la preocupación por definir un ASC y plantear alternativas de abordaje no ha sido suficientemente revisitada. Es paradójico que ello ocurra teniendo en cuenta la renovación conceptual que se observa en la historia social, la sociología de la acción y la geografía y que, precisamente, pueden suministrar herramientas en orden a retomar algunas problemáticas centrales. ¿Cuáles dimensiones pueden aproximarnos a la trama constitutiva de un ASC? En un trabajo anterior, de nuestra autoría, iniciamos esa discusión a partir de un bagaje teórico, pero no se avanzó en su dinámica relacional ni en la discusión de otros

\footnotetext{
intersubjetivas" (p. 17).

4 Jesús Ibañez integra la nómina de los más reconocidos sociólogos españoles del siglo XX, abocado a desarrollar sus aportes desde la metodología sociológica cualitativa, y proponiendo como instrumento de investigación el socioanálisis.

${ }^{5}$ Es el caso del concepto actor-red mediante el cual se incluye en el tejido social tanto a los sujetos sociales como las entidades producidas por la naturaleza y los objetos no-humanos, artefactos, dispositivos, tecnologías, equipos, instrumentos, bienes, productos, etcétera. (POZAS, 2018) La teoría del actor red, Actor-Network Theory (ANT), fue impulsada por Bruno Latour, Michel Callon y John Law entre otros. Javier Lezaun aclara que se trata de una teoría social en curso. La misma se inició a fines de los setenta como una corriente de investigación abocada al estudio social de las prácticas técnicas y la creación de conocimientos científicos. Para un análisis sobre el recorrido epistemológico de dicha teoría, véase LEZAUN, 2019.

${ }^{6}$ Algunas producciones académicas entre los años ochenta y noventa replicaban en sus estudios particulares ese enfoque centrado en las clases como sujetos colectivos. Véase, por ejemplo, CAÍNZOS LÓPEZ, 1989; VILAS, 1995.

${ }^{7}$ Esta sola categoría es de por sí objeto de un sinnúmero de producciones y de tipologías ya que existe una pluralidad de formas de organización y de acción, según un amplio abanico de expresiones empíricas. Además, pueden abarcar desde formas asociativas muy poco formalizadas a expresiones más institucionalizadas. Pueden localizarse en ámbitos urbanos como rurales, describiendo aquí nuevas problemáticas como lo son los movimientos contestatarios al agronegocio y las nuevas ruralidades (GIARRACCA, 2017); pueden vincularse fuertemente al territorio (FERNANDES, 2005); expresarse dentro del capitalismo o proclamarse antisistémicos y anticapitalistas (AGUIRRE ROJAS, 2010).

${ }^{8}$ Véase el estudio de DUBAR y TRIPIER (1998).

${ }^{9}$ La densidad de los estudios cooperativistas torna imposible referenciarlos aquí. Véase una referencia clásica sobre el tema en GIARRACCA (1994).
} 
alternativos. (BASCONZUELO, 2019)

Este trabajo intenta dar respuesta al interrogante planteado desde una perspectiva de análisis relacional correspondiente al campo de la historia social. ${ }^{10}$ En ese marco, el propósito general del artículo es proponer algunas dimensiones de análisis para el estudio de la configuración socio histórica ${ }^{11}$ de un ASC mediante herramientas conceptuales interdisciplinares y a la luz de nuestra reflexión con base en publicaciones de mi autoría y proyectos de investigación en ejecución. Lo conceptual adquiere, por lo tanto, en este trabajo una dimensión central.

Se fundamenta así un esquema metodológico que comprende tres dimensiones de análisis y sus respectivos indicadores. Por un lado, dimensiones situadas, las cuales comprenden: a) el ASC y la experiencia colectiva, que remite a las preguntas del perfil y nivel organizativo de dicho actor y las características de la acción colectiva en un momento histórico concreto; b) la territorialización, es decir, el espacio de relaciones donde efectivamente tiene lugar la constitución del ASC y desde donde se pueden abordar dos indicadores importantes como lo son las escalas y las redes que pueden constituir los ASC en la búsqueda de aliados. Por otra parte, se sitúa una dimensión macrosocial donde queda comprendido el contexto histórico, el cual proporciona indicadores para responder a la pregunta de las circunstancias socio políticas, el diseño de políticas públicas, el mapa de actores colectivos de época, las tradiciones culturales que enmarcan en el nivel general y local la emergencia de un ASC. Finalmente, cabe observar las dimensiones transversales, es decir, aquellas que resultan explicables a partir de las situadas y a la vez pueden incidir sobre ellas: a) la identificación del ASC que lleva a interrogarse por los procesos de autoidentificación y la identidad atribuida tanto a sus antagonistas como a sus aliados; b) la temporalidad del ASC que implica preguntarse por la trayectoria histórica que describe un ASC en su génesis, desenvolvimiento y posible reconfiguración.

La investigación es cualitativa. La estrategia metodológica empleada se sustenta en un análisis crítico de la bibliografía seleccionada que aporta los conceptos teóricos que conduce en un segundo momento a la delineación de las dimensiones e indicadores de análisis antes señalados. No obstante, esta investigación encierra por cierto algunos límites precisos. Se trata de una propuesta teórica provisoria, aunque fundamentada en los resultados de nuestras investigaciones y proyectos en curso, que requiere de la contrastación con nuevos

\footnotetext{
${ }^{10}$ El análisis relacional es un paradigma reciente en la historia social que se ocupa de estudiar las relaciones efectivas entre los actores sociales, sus interacciones, sus vínculos. Aquí resulta aplicado a la relación entre dimensiones de análisis sociales que deben ser abordadas de manera relacional para comprender el proceso de configuración de un ASC. Un referente de dicha teoría es José María IMíZCOS BEUNZA (2011), con su particular historia sobre redes sociales. Dicha perspectiva teórica también se halla presente en la sociología, como alternativa a la sociología de la acción y sociología de los sistemas. Véase una explicación de los fundamentos de dicha teoría en HERRERA GÓMEZ (2001) y algunos de sus referentes en (WAGNON, 2018).

${ }^{11}$ Se entenderá aquí la noción de "configuración socio histórica" a partir de una readaptación de la categoría "configuración", sugerida por Norbert Elías (1991). Desde una perspectiva relacional, la cual precisamente resulta de pertinencia para nuestro estudio, que lo lleva a resaltar las interdependencias entre individuo y sociedad y sus vínculos, su teoría se contrapone a las visiones que sólo destacan la autonomía del individuo respecto de las estructuras sociales, así como también a las que subrayan el peso de esas últimas.
} 
estudios de caso para nuevamente interpelar, ampliar o profundizar el mapa conceptual aquí propuesto.

La estructura del trabajo implica un recorrido adecuado para el logro del propósito central. En el primer apartado se destaca el papel de la acción como punto de partida para estudiar la emergencia de un ASC. Para ello se revisan críticamente algunos aportes previos según un criterio historiográfico y se fundamenta la expresión "experiencia colectiva situada" como más apropiada para desentrañar las dinámicas que la misma comprende en un espacio y tiempo concreto y con la referencia a la cuestión de la identificación. El segundo parágrafo se aboca a tratar otra dimensión que compete al proceso de configuración del ASC, su territorialidad y se argumenta cuáles prácticas aportan elementos de análisis para situar la experiencia colectiva y proyectarla en un proceso que compete al espacio social. Finalmente, se abordan las dimensiones transversales, es decir, la identidad y la temporalidad, siendo las que tienen capacidad explicativa tanto para aportar coordenadas de relación con el ASC y con la acción colectiva que lo identifica.

\section{Las dimensiones situadas}

La acción como punto de partida y la experiencia colectiva situada

Consideramos que la dimensión que remite de manera inequívoca a la configuración y participación de un ASC es la "acción", tema que ha sido profusamente trabajado y abordado, sobre todo en el campo de la sociología. El propósito de este apartado es efectuar un recorrido sintético, pero crítico, respecto de las contribuciones más sobresalientes en el tema para fundamentar, al final, una noción que se sustenta en la perspectiva interdisciplinar.

Los análisis sobre acción colectiva y la pregunta por los elementos que la integran es un problema en sí mismo para la teoría social. Recoge un vasto conjunto de aportes teóricos, según diferentes paradigmas. ${ }^{12}$ Siguiendo a QUIROGA (2013) puede decirse que durante el siglo XIX y dentro del campo de la sociología, los trabajos de Marx y de Le Bon habrían sido los primeros en tratar de comprender los comportamientos colectivos, seguidos por los trabajos de Neil Smelser y Ted Gurr, ya a mediados del siglo XX. Luego, en la década del setenta, se delinean dos nuevas tradiciones interpretativas siendo representadas una, por la escuela norteamericana de la interacción estratégica con un énfasis en la teoría de la movilización de recursos (McCarthy y Olson), o bien en la movilización política (Tilly, Mc Adam y Tarrow), así como en los abordajes culturales (Obershall, Gamson y Snow). De otro lado, la corriente europea que recoge autores destacados e influyentes particularmente en los estudios renovados de actores y movimientos sociales, como Touraine, Rudé, y de la

\footnotetext{
12 Un análisis de esos aportes desde la perspectiva sociológico-histórica, véase en GARCíA GONZÁLEZ (2017).
} 
identidad colectiva como Melucci, Offe, Castells, Borja y Thompson. (QUIROGA, 2013, p. $34)^{13}$

Ahora bien, dos planteos entrelazados cobran relevancia aquí: ¿qué se entiende básicamente por acción colectiva? ¿Cómo inicia el proceso constitutivo de un ASC? Desde la clásica definición de CHARLES TILLY (1978) dos aspectos parecen constituirse en centrales al momento de considerar una acción colectiva y la relación con un actor social: episodios que acontecen en el marco de un colectivo social y un efecto performativo de aquella acción sobre el actor que la emprende. En palabras del citado historiador: "se trata de episodios no rutinarios que ocurren como parte de la interacción entre personas y grupos antes que como una performance individual"; y además "los participantes aprenden, innovan y construyen historia en el propio curso de la acción colectiva" (p. 14). A dicha acción el autor le agrega carácter discontinuo y contencioso. ${ }^{14}$ Desde una perspectiva sociológica actual, FEDERICO SCHUSTER (2005) entiende por acción colectiva "cualquier acción que requiere de la participación cooperativa de la menos dos individuos para su realización” (p. 43).

EI ASC no se entiende disociado entonces de la acción colectiva. En este sentido, ESTER GARCÍA SÁNCHEZ -politóloga española- (2007) lo afirma categóricamente: "no todo grupo de individuos puede ser considerado de manera automática un actor" (p. 201). ${ }^{15}$ Entonces, "el término actor se define a partir de la idea de acción", por lo que un actor es "todo aquel sujeto que actúa; es el sujeto de la acción" (p. 201).

La autora avanza en un punto más, remitiendo a la categoría de "actor colectivo", por lo que sostiene:

\begin{abstract}
Podemos concluir en considerar como actor (colectivo) a aquella entidad cuyos miembros están integrados en torno a similares -o, al menos, convergentesintereses, percepciones y creencias con respecto a un problema; que cuenta con cierto grado de organización y recursos y con mecanismos para la resolución de conflictos internos; que tiene los medios y la capacidad para decidir y/o actuar intencionada y estratégicamente para la consecución de un objetivo común como unidad suficientemente cohesionada, lo que le identifica y diferencia frente al resto y a la que, por tanto, se le puede atribuir alguna responsabilidad por sus decisiones y/o actuaciones. En otras palabras, un actor es una unidad de decisión-acción
\end{abstract}

\footnotetext{
${ }^{13}$ La autora adscribe a la teoría laclauniana de la hegemonía y desde esta perspectiva considera otro enfoque alternativo para entender la acción colectiva, a partir de la constitución de identidades políticas, lo cual supone reparar en la construcción de equivalencias entre demandas diversas y el trazado de fronteras políticas.

${ }^{14}$ Cabe acotar que el carácter contencioso particulariza, para algunos autores, una modalidad de acción colectiva que es la protesta social. Al respecto, una vasta producción se constituye actualmente en cuerpo referencial para los estudios de la protesta social en Europa, América latina y Argentina. Solo a modo referencial para el caso europeo puede mencionarse a TRAUGOTT (2003). Para el ámbito argentino, cabe la mención -entre otros- de los trabajos de AUYERO (2002), SCHUSTER Y OTROS (2005). Ambos se constituyen en una inevitable fuente de consulta, ya que representan dos formas distintas de abordaje para una misma estrategia metodológica que es el estudio de casos. En el primer autor, porque se tiene en cuenta el proceso político como factor detonante entre el contexto estructural y el surgimiento de la acción beligerante, en el segundo autor porque se construyen categorías de aplicación a partir de una exhaustiva tarea de registro documental.

${ }^{15}$ Véase un análisis exhaustivo acerca de los referentes teóricos principales en el campo de la sociología que trabajaron el concepto de actor en: GARCíA SÁNCHEZ (2007).
} 
responsable (GARCÍA SÁNCHEZ, 2007, p. 206). ${ }^{16}$

Con foco en el ASC y desde el paradigma que resalta la movilización de recursos, el sociólogo alemán KLAUS EDER (1991) se preguntaba en los años noventa cómo emergen los actores colectivos en la realidad social y cómo se relacionan con esta realidad. En su opinión, la acción colectiva juega un papel relevante, al decir: "no vamos a comenzar con la construcción teórica de los actores colectivos como portadores de la acción colectiva, sino, por el contrario, con la construcción teórica de la acción colectiva dentro de la cual emerge el actor colectivo (p. 126).

Para Eder, hay tres fases en la producción y reproducción de actores colectivos:

La primera fase se puede describir como el proceso de construcción de un actor colectivo a través de la acción conjunta. Este proceso se puede describir en términos de la interrelación de actores individuales que actúan juntos para producir un bien colectivo. La acción orientada a la producción de este bien es una acción colectiva. La segunda fase incluye el proceso de identificación de un actor colectivo mediante la definición de los límites de la acción colectiva. La acción colectiva ya no se limita a su funcionamiento interno, sino que traza los límites entre la acción colectiva y su entorno social. La tercera fase se caracteriza por los procesos que permiten la reproducción de esta identidad [...] (EDER, 1991, pp. 11 y 136). ${ }^{17}$

Al preguntarnos por el ASC se trata de indagar en el "Quién de la acción colectiva" y en el señalamiento de los indicadores constitutivos, tal como afirma el sociólogo argentino GABRIEL NARDACCHIONE (2005). En su opinión, ese actor resulta de "un proceso reflexivo en el cual un grupo se reconoce como un colectivo que está sufriendo un proceso de identificación". Ese colectivo social "busca a su vez consolidar el Nosotros de la acción" (p. 89).

La sociología contemporánea continúa ocupándose de la acción colectiva en dos direcciones. Por un lado, los presupuestos de la sociología pragmática, con su referente principal LAURENT THÉVENOT (2016), y a través del texto de su autoría "La acción en plural", se aboca a las diversas formas de involucramiento por las cuales transita una persona. Esta perspectiva descarta los enfoques según los cuales las estructuras imponen los formatos de la acción, aunque al mismo tiempo rechaza los planteos relativistas porque los actores no despliegan arbitrariamente sus intereses o sus intenciones. La noción de involucramiento implica "postular una relación con el mundo actualizada por la persona en acción y formas de acción posibles dentro del marco de una situación" (p. 254). Así, el autor describe tres niveles de involucramientos que permiten explicar los registros de acción mediante los cuales las personas transitan desde lo familiar a lo público, pasando por la comunidad. ${ }^{18}$

\footnotetext{
${ }^{16}$ Esta definición resulta aplicable, sobre todo, para los actores que presentan algún grado de integración y organización institucional, y cuyas acciones implican intención y decisión; pero no podría ser extendida para denominar a aquellos que se relacionan con iniciativas espontáneas, a quienes la autora encuadra bajo la noción de "actores nominales" (p. 210)

${ }^{17}$ La traducción del texto en francés original es nuestra.

${ }^{18}$ En un primer nivel ubica a la persona en su entorno familiar, donde hay vínculos particulares y lazos
} 
También la historia social se ha ocupado de elaborar paradigmas para dar cuenta de los procesos que involucran a los ASC. Uno de ellos es la "teoría de la práctica" (SPIEGEL, 2006), una perspectiva que discute el papel determinante de las estructuras lingüísticas en la vida social, y si bien reconoce que las tradiciones culturales y herencias sociales ejercen su influencia sobre el actor, rehúsa otorgarles un papel determinante. Allí es donde se abre paso nuevas categorías como la de "experiencia" que significa un giro hacia la revalorización de las prácticas, que en su formulación estricta asume los postulados del giro lingüístico pero los reinterpreta a favor de la historia social, colocando acento en "la naturaleza históricamente generada y siempre contingente de las estructuras de la cultura", con lo cual vuelve a revalorizar el papel de los procesos, los agentes, el cambio y la transformación.

De acuerdo entonces con estas consideraciones un elemento fundamental para considerar la configuración de un ASC es la acción que lleva a cabo ese colectivo. A partir de estudios que revisan algunas lecturas tradicionales y sostienen que la acción colectiva "configura un ámbito de estudios interdisciplinario por excelencia" (QUIROGA, 2013, p. 27), proponemos el término "experiencia colectiva situada" para dar cuenta de una acción sostenida por un conjunto de individuos con un propósito común que, según un nivel de organización inorgánico o institucionalizado, se proyecta en un espacio de relaciones sociales $y$ en un tiempo concretos para recorrer una trayectoria en cuyo transcurso el ASC se configura y/o reconfigura. ${ }^{19}$

Al tratarse pues de un proceso -he aquí el matiz que pretendemos resaltar al tratarse de un enfoque sociohistórico- el ASC se configura en función de los siguientes indicadores: a) la acción; b) el formato organizativo; c) la identificación. Con estos indicadores el ASC describe una trayectoria influenciada por los contextos de pertenencia pero con capacidad para incidir o impactar en ellos.

\section{La territorialización de la experiencia situada}

El concepto de territorio y otro conjunto de nociones asociadas que se desprenden de recorridos teóricos diversos (territorialización, desterritorialización, territorios-red, territorios excluidos) es elocuente del abanico de conceptos que se recrean para aludir a situaciones y contextos que revelan los diferentes usos y apropiaciones que tienen los espacios habitados y experimentados.

emotivos. Se trata de un involucramiento apoyado en los espacios familiares y de intimidad. Un segundo nivel se amplía para tomar en cuenta al otro/os, y aquí caben las regulaciones, el plan de acción de la persona en su relación con la comunidad donde se vincula e inserta. Por último, el espacio público donde las acciones de los individuos se ven reguladas por la comunicación, las ideas y los valores comunes, donde juegan las argumentaciones la deliberación, las justificaciones, las críticas. Un nivel donde la comunicación juega un papel importante (THÉVENOT, 2016, p. 264-265).

${ }^{19}$ Estas consideraciones se infieren de nuestros trabajos sobre cooperativismo de crédito, una modalidad de organización que en el marco del asedio de políticas financieras de los años setenta vio desarticular sus entidades y reconvertirse en formato bancario. 
Uno de los referentes principales del enfoque sociológico histórico, CHARLES TILLY (1995), consideraba que las acciones colectivas se hallan históricamente situadas y se desarrollan en los "repertorios parroquiales" (p. 14), es decir, en los marcos locales donde los participantes construyen sus vinculaciones diarias y organizan sus reclamos.

El célebre geógrafo baihano MILTON SANTOS (1996) había advertido que las relaciones sociales son formadoras de los sistemas de acciones, producen espacios y allí los grupos sociales materializan sus intencionalidades, sus lecturas que pueden ser dominantes o no. Nótese pues esta concepción del que se atribuye al territorio como productor de representación y de sentido y que implica una disputa ya que es apropiado por una determinada relación social que lo produce.

Actualmente, los entornos locales, los lugares, donde acontecen las acciones colectivas se estructuran conforme fuerzas y actores que los atraviesan en un sentido global, tal como lo postuló y estudió Doreen Massey. (ALBET Y BENACH, 2012) Por otro lado, y tras el giro espacial que aconteció en la disciplina geográfica, que significó desde los años setenta ofrecer una mirada diferente sobre el espacio, más atenta a las relaciones sociales, a las prácticas socio espaciales y a los conflictos y resistencias que plantean los ASC en clave territorial, el estudio de estos actores proyectos novedosas categorías. Así se abordan "movimientos socio territoriales" y "movimientos socio espaciales" en procura de desentrañar de qué modo esos actores operan, reivindican, conviven, luchan en diferentes direcciones en un territorio que es percibido en sentido multidimensional. (FERNANDES, 2005; PORTO-GONÇALVES, 2006) ${ }^{20}$

También se revisitan otras, aunque dotándolas de nuevos alcances, como es el caso de la escala, de la cual se ha dicho no refiere simplemente una alusión cartográfica, sino que "es algo que se produce y se disputa", que "expresa cambios en la geometría del poder social, surge como el sitio para el control y la dominación, pero también como la arena donde la cooperación y la competencia encuentran un empate frágil". (FERNÁNDEZ y BRANDÃO, 2010) A partir de las escalas el ASC puede crear y recrear estrategias de acción colectiva que se fundamentan en articulaciones y alianzas que atraviesan el espacio y generan así una política de escala. (LOPES DE SOUZA, 2013)

Queda claro para los estudiosos de la geografía que los actores sociales colectivos producen sus territorialidades, construyen sus propias condiciones materiales y simbólicas de existencia. La territorialidad se presenta como un producto histórico construido a partir de tramas políticas y espaciales con un peso constitutivo en la estructuración de los grupos sociales. Las acciones colectivas construidas a nivel escalar o multiescalar suponen estrategias de redes, donde es central la articulación entre sujetos sociales situados en diferentes lugares que se asocian y se conectan. La escala entonces funge como mecanismo organizativo y como recurso estratégico para viabilizar las acciones colectivas. (SOUZA COELHO NETO, 2018)

\footnotetext{
${ }^{20}$ Para un análisis de las estrategias escalares de ASC en el mundo agrario argentino, véase ASCOLANI (2009)
} 
Resulta provocador de nuevos enfoques la noción de redes que articulan los actores colectivos con propósitos de interacción y complementariedad (COENEN-HUTHER, 1993); así como también redes para su organización (LAZEGA, 1994) que denotan formas de articulación inter organizacionales como en las movilizaciones en el espacio público, en la captación de recursos organizativos, y explican el pasaje del sujeto identitario al sujeto plural. En las redes circulan entonces dinámicas solidarias, de reciprocidad pero también puede ser de conflicto, y ello genera una dinámica que puede trasponer las fronteras territoriales articulando acciones locales, regionales, nacionales y transnacionales. (SCHERER-WARREN, 2006)

En síntesis, los ASC construyen socialmente los espacios en los que desenvuelven sus trayectorias en la medida que las acciones colectivas de las cuales son impulsores y partícipes recalan territorialmente, y según el grado de organización y el nivel de institucionalidad que adquiere anudan contactos, envuelven redes de trabajo colectivo y pueden llegar a fortalecer prácticas de acción en diferentes escalas. ${ }^{21}$ Esa territorialidad es del ASC es a la vez, dialógicamente, de la acción situada; por lo tanto incide en la configuración de las identidades y determina flujos donde circulan redes y escalas de acción.

De aquí se infieren pues los principales indicadores de la territorialidad de un ASC: a) posición localizada; b) construcción de redes; c) representación escalar.

\section{La dimensión macro: el entorno construido}

Los aspectos macrosociales, el contexto histórico, se constituyen en una preocupación preliminar para los historiadores cuando debe situar los actores sociales y sus acciones en un nivel explicativo general y articularlos con la sociedad de su tiempo. De hecho, durante buena parte del siglo $\mathrm{XX}$, quienes se ocupan de esta problemática colocan foco en las estructuras económicas y sociales, por lo que los paradigmas vigentes consensuaron una mirada determinista de la estructura sobre la agencia humana.

Las contribuciones de la sociología francesa, en tal sentido, trazan horizontes y proporcionan lineamientos que, luego, autores europeos y latinoamericanos adoptan. La sociología de las organizaciones recoge buena parte de aquella prédica epistemológica. MICHEL CROZIER y ERHARD FRIEDBERG (1977) las organizaciones son instrumentos que los individuos forjan para resolver la cooperación y perseguir objetivos colectivos, mientras el sistema es el campo estructurado; pero de cualquier modo la organización condiciona y circunscribe la acción colectiva.

Un segundo marco interpretativo es la sociología de la acción. Si en una de las obras que resulta ser cantera de ideas para las tesis que argumentan la interdependencia entre los

\footnotetext{
${ }^{21}$ Nuestros trabajos sobre organizaciones vecinales en la ciudad de Río Cuarto dan sustento a las afirmaciones aquí expresadas.
} 
actores y el sistema, "El regreso del actor", ALAIN TOURAINE (1987) aventura que las clases sociales -en cuanto ASC- "no se limitan a reaccionar frente a situaciones, sino que también las engendran" (p. 49), por medio de otras dos producciones posteriores parece distanciarse de esa premisa. En efecto, en 1998, en la ciudad de Montreal, pronuncia una conferencia donde sostiene que "nos definimos más y más como actores no sociales, definidos por status adscritos más que alcanzados" (TOURAINE, 2006, p. 95), y atribuye esta situación a la racionalización tecnológica, económica y administrativa, destacando así el proceso de subjetivación frente a las fuerzas del mercado y los valores comunitarios. En otro texto vuelve a insistir que el principio de legitimidad de las conductas sociales se ha trasladado de la sociedad al propio individuo, para concluir "es el actor en persona, quien se atribuye esta capacidad de autolegitimación", es decir, "el sujeto" (TOURAINE, 2005, p. 72)

Desde la ciencia política, también en los años setenta, se señala que es la coyuntura el elemento que explica la aparición de los ASC del tipo movimientos sociales. Se denomina "estructura de oportunidades políticas" según SIDNEY TARROW (1998) a la dimensión el entorno político que estimula o desalienta la acción colectiva, por lo que se hace hincapié en los recursos exteriores con que cuentan, además de la posibilidad de encontrar aliados potenciales y la influencia de la coyuntura mundial.

En los años noventa, conforme algunas corrientes se distancian de las teorías más puras del estructuralismo, se instala la tesis acerca de la autonomía del sujeto y, además, se discute que las clases sociales pueden ser los únicos ASC. En palabras del sociólogo alemán KLAUS EDER (1991) expresa:

\footnotetext{
Nos enfrentamos a la existencia de actores colectivos (plurales) que no tienen nada que ver ni con la sociedad civil ni con las clases. Parecen existir independientemente de tales condiciones estructurales y culturales, lo que hace que sea necesario reaccionar a esta teoría. El simple determinismo de la estructura social debe ser excluido. El problema es descubrir cómo las estructuras desempeñan un papel en el auge y caída de los movimientos sociales y otros actores colectivos en las sociedades modernas (EDER, 1991, p. 123).
}

La visión de Eder permite ampliar un poco más acerca de ese paradigma del conocimiento imperante ya que en orden a explicar el accionar de los sujetos sociales, se amplifica el interés por los aspectos simbólicos y lingüísticos de la acción social.

A pesar del impacto que tienen las corrientes teóricas apegadas a los factores culturales y que intentan centrar en el sujeto, los enfoques contextuales no pierden vigencia, solo que introducen en sus teorizaciones ese necesario cruce -tal como advierten- entre dimensiones locales y globales. El sociólogo español JULIO ALGUACIL GÓMEZ (2006, p. 43), un estudioso de los movimientos sociales contemporáneos en el ámbito europeo, resalta que los contextos juegan un papel importante y considera que los ASC del tipo movimientista responden a esos procesos sociales. En sus palabras: "se presentan como nexo de asociación, como motivadores y a la vez interpretadores de las síntesis que se producen, que intuyen y que se construyen, entre los pares de conceptos paradójicos local/global" (p. 44). 
El debate alcanza al campo de la historia social. Desde aquí BEATRIZ MOREYRA (2014) considera que en el marco de un renovado deslizamiento hacia lo social como categoría analítica central, la tendencia es revalorizar la capacidad explicativa de contexto. Este criterio cobra vigencia porque, en opinión de la autora:

sin la apelación a la reconstrucción y de los contextos históricos, el caso individual culturalmente resonante no puede hacerse históricamente significativo. Toda percepción, toda construcción de significado ocurre dentro de contextos históricamente contingentes y sociológicamente situados, producidos por agentes que actúan como actores intencionales y resignificantes semánticos de los sistemas de signos y discursos históricamente construidos $(p, 174)$.

Así, la autora apela a una visión más integradora donde la reformulación de lo social implica la necesidad de ponderar "el poder condicionante y explicativo de las realidades sociales no discursivas que imponen límites"; un criterio que en términos teóricos metodológicos significa "tener en cuenta la causación social en la explicación de las realidades sociales" ( $p$. 175).

La sociología norteamericana que fuera crítica de las perspectivas estructuracionistas ha colocado el foco también en esa dimensión que entraña lo espacial y el lugar desde donde acontecen las acciones colectivas. En tal sentido, WILLIAMS SEWELL (2006), emplea la noción "entorno construido" (p. 69) que nos resulta de utilidad para plantear cómo los ASC incidencia en sus espacios a partir de las acciones que emprenden.

Según el autor, las actividades humanas no se explican únicamente en virtud del lenguaje y las producciones discursivas: "son simultáneamente, actos en y sobre entornos materiales". Y añade: "lo que convierte a la acción semiótica en histórica es que tiene la capacidad de transformar el entorno en que tiene lugar" (p. 66). Insiste en otro momento sobre el mismo punto para dar lugar a una reflexión que nos ubica en la importancia de las acciones performativas:

\footnotetext{
los seres humanos literalmente construyen y reconstruyen su entorno físico [...] al actuar dentro de esas formas dadas y específicas de vida no sólo reproducimos, sino que también alteramos las rutinas, reemplazamos o reformamos las instituciones, aprendemos a pensar de manera diferente e inventamos nuevas técnicas de producción (p. 70).
}

Entonces, consideramos que la configuración de los ASC debe estar atenta a esos entornos construidos, pero sin otorgarles factor determinista. A esos entornos donde las dinámicas económicas, sociales y culturales explican literalmente -aunque sólo en partecómo y por qué aparece en la escena social un ASC. Ese valor explicativo de lo contextual histórico no puede dejar de lado la capacidad performativa ${ }^{22}$ de las prácticas colectivas

\footnotetext{
${ }^{22}$ La noción de performatividad es entendida aquí en sentido genérico, como la capacidad de una entidad para transformar el entorno, y no por referencia explícita a la teoría de la performatividad cuyos referentes contemporáneos son Austin, Butler y Derrida.
} 
encauzadas, es decir, el valor que cobran decisiones y acciones para incidir en ese mismo entorno, hasta llegar a provocar no solo tensiones sino también cambios. Aquí, los acontecimientos ${ }^{23}$ irrumpen con un efecto de incisión sobre la temporalidad para enhebrar nuevos procesos, de la mano de ASC. ${ }^{24}$

El entorno construido no es entonces un elemento eterno a los ASC, explica una de sus tramas constitutivas y configuracionales, por lo que pueden estudiarse: a) condiciones políticas; b) relaciones de producción; c) estructura social; d) tradiciones culturales; e) actores globales.

\section{Las dimensiones transversales}

\section{Identidades e identificación}

La identidad es uno de los grandes temas en la literatura histórica y sociológica. ${ }^{25}$ Plantear la identidad en relación con la configuración socio histórica de un ASC es adentrarse en la perspectiva subjetiva de análisis. En relación con los ASC aparece cuando estos sujetos históricos transitan por la constitución de un "nosotros" frente al "otro"/"otros". Para algunos, la cuestión identitaria es resultado y producto de la acción colectiva, por cuanto en el transcurso de la lucha se van articulando los elementos de homogeneización que acercan a los colectivos; para otros es el punto de partida mismo que encauza dichas acciones. ${ }^{26}$

El debate en las ciencias sociales sobre el tema es amplio. Las miradas son diferentes. Por ello es importante la pregunta, no solo por los componentes que convergen para construir la identidad de un actor social, sino las lógicas internas y externas constitutivas.

En este punto invocamos el aporte de STUART HALL (1996) quien, desde una perspectiva sociológica enmarcada en los estudios culturales, considera "preferible" abordar el concepto de "identificación" antes que el de identidad. En tanto campo semántico demasiado complejo, aquél "se construye sobre la base del reconocimiento de algún origen común o unas características compartidas con otra persona o grupo o con un ideal" (p. 15) Se trata entonces de "una construcción", "un proceso de articulación nunca terminado" que requiere "condiciones determinadas de existencia, que incluyen los recursos materiales y simbólicos necesarios para sostenerla" (p.15). Es condicional y se afinca en la contingencia, según sus palabras. Pero, además, sigue otra lógica para consolidar aquel proceso de

\footnotetext{
${ }^{23}$ Los acontecimientos cumplen un papel importantísimo en el proceso de cambio social, como lo señala Peter Burke (2007: 238).

${ }^{24}$ Nuestros trabajos sobre el Cordobazo en Río Cuarto sustentan dicha afirmación.

25 En este apartado se profundizan aspectos del tema desarrollado en otro artículo de nuestra autoría (BASCONZUELO, 2019), en este caso para plantear los ejes de análisis a considerar cuando se trata de abordar la configuración socio histórica de un ASC.

${ }^{26}$ Véase un análisis sobre esas visiones según las teorías sociológicas contemporáneas en IGLESIAS (2007).
} 
articulación, pues "necesita lo que queda afuera, su exterior constitutivo" (p. 16).

Ese sentido de proceso según el cual puede interpretarse la identificación, cabe de igual manera para abordar la identidad. Concepto "estratégico y posicional", se constituye de múltiples maneras a través de discursos, prácticas y posiciones diferentes"; añade también que "está sujeta a una historización radical y a un constante proceso de cambio y transformación" (p. 17). En un cruce con las tradiciones, agrega: "las identidades se relacionan tanto con la invención de la tradición como con la tradición misma" y en una relación con lo histórico afirma: "son producidas en ámbitos históricos e institucionales específicos, en el interior de formaciones y prácticas discursivas específicas mediante estrategias enunciativas específicas" (p. 18).

Finalmente, sin un "otro" exterior la identidad es incompleta. A partir de un diálogo con Derrida, Laclau y Butler, sostiene: "las identidades se construyen a través de la diferencia", lo cual significa considerar "la relación con el Otro, la relación con lo que él no es, con lo que justamente le falta, con lo que se ha denominado su afuera constitutivo" (p. 18). Define entonces las identidades como:

las posiciones que el sujeto está obligado a tomar, a la vez que siempre «sabe» que son representaciones, que la representación siempre se construye a través de una "falta», una división, desde el lugar del Otro, y por eso nunca puede ser adecuada idéntica- a los procesos subjetivos investidos en ellas (p. 21)

A fines de los noventa MANUEL CASTELLS (1999) entiende que las identidades son "fuentes de sentido para los propios actores" y son construidas por ellos mismos mediante un proceso de individualización que es básicamente un "proceso de construcción del sentido atendiendo a un atributo cultural al que se da prioridad sobre el resto de las fuentes de sentido" (p. 28). Aclara también que para un individuo determinado o un actor colectivo puede haber una pluralidad de identidades y ello no se confunde con los roles sociales.

Circunscribiendo su análisis a la identidad colectiva y subrayando el carácter de "construcción" donde los componentes culturales, pues, juegan un papel importante su estudio permite esclarecer desde qué lugar los actores colectivos construyen sus identidades y cómo realizan dicho proceso. Allí puntualiza que la construcción de identidades "utiliza materiales de la historia, la geografía, la biología, las instituciones productivas, la memoria colectiva y las fantasías personales, los aparatos de poder y las relaciones religiosas". Luego, los actores sociales procesan esos materiales, es decir, "los reordenan en su sentido" para lo cual cuentan las determinaciones sociales y los proyectos culturales en su marco espacio temporal (p. 29).

Para Castells, entonces, la identidad colectiva es un proceso de construcción social, el cual tiene lugar en un contexto marcado por las relaciones de poder, del que se deducen tres procesos diferentes: "una identidad legitimadora" que procede de las instancias institucionales de dominación de la sociedad; "una identidad de resistencia", encarada por aquellos actores que se encuentran en posiciones devaluadas frente a la dominación y "una 
identidad proyecto" que es construida por los actores sociales basándose en los materiales culturales de que disponen, y a partir de allí buscan una nueva identidad que produzca la transformación de toda la estructura social (p. 30). En su análisis también incluye otras identidades: las territoriales asociadas a la comunidad local y la corporal en vinculación con la sexualidad.

La cualidad identitaria como elemento impulsor de la acción colectiva es una tesis también expresada por el sociólogo alemán KLAUS EDER (1991), al decir:

\begin{abstract}
Al definir los límites de la acción común, se crea una identidad que transforma la acción colectiva en un actor colectivo. La clave para una teoría más elaborada de la formación de un actor colectivo se encuentra en este micro nivel de análisis de identidad grupal. Deseo explicar esta teoría más elaborada y desarrollar la teoría de la identidad de grupo hacia una teoría de la autoproducción y la reproducción de los grupos a través de prácticas cognitivas, y en la forma idealmente ejemplar, a través de procesos de aprendizaje colectivo (p. 131).
\end{abstract}

La teoría del discurso ha dejado contribuciones al respecto, donde la función del recurso discursivo se señala como fundante de la secuencia formativa. La identidad, según LEONOR ARFUCH (2002) se abre "a la temporalidad, a la contingencia, a una posicionalidad relacional" y se construye en el discurso (p. 21). La relación con el otro que introduce "la diferencia" se explicita también en la teoría política crítica de BENJAMíN ARDITI (2009), para sostener que "toda identidad se establece a partir de un esquema relacional" (p. 37). Añade otros rasgos que nos aproximan aún más a la dimensión temporal, y como tal histórica:

es el efecto de vínculos de todo tipo, culturales, políticos, religiosos, comerciales, etc. que cambian con el tiempo [...] son construcciones abiertas al cambio [...] las identidades colectivas son contingentes, son algo inacabado por cuanto siempre están en construcción a través de continuo proceso de identificación. [...] pasan de un estado a otro, pero tan lentamente que parecen conservar una estabilidad (pp. 38-39).

Otros cientistas sociales amplían un poco más esta base teórica para subrayar la idea de movilidad, transformación, cambio y "proceso de constitución nunca acabado" que se atribuye a la identidad. Así, la identidad es "contextual, situada, momentánea, abierta y flexible" (NAVARRETE-CAZALES, 2015, pp. 471 y 477). Para LACLAU y MOUFFE (2000) las identidades no consiguen una constitución plena en la medida que hay un antagonista.

Por otro lado, podría recuperarse otra lectura de la identidad que la coloca en otro proceso: la exterioridad de sus registros subjetivos. En la instancia que significa movilizarse un "nosotros" contra un "ellos" se validan "los valores y el estilo de vida del grupo", como sostiene ERIK NEVEU (1996, p. 104), que pueden "hacerse públicos de múltiples maneras, entre un registro crítico que puede asociarse a la idea de estrategias de provocación, y un registro educativo que se emplea para hacer percibir la identidad grupal".

De la lectura de los autores seleccionados pueden señalarse claves importantes para encarar el estudio de la identidad. El análisis del discurso del ASC se constituye en una de las 
fuentes para el estudio de la identidad, aunque no la única. El simbolismo de imágenes, rituales, etc. también cuenta. Los indicadores de análisis que deben ser considerados están relacionados con las posiciones y las representaciones del ASC: a) las enunciaciones autoreferenciales; b) las tradiciones propias; c) los marcos históricos de referencia; d) la configuración del antagonista; e) valoraciones identitarias. Finalmente, para que la identidad se entienda como proceso debe incorporar la temporalidad, es decir, los cambios, las continuidades que operan tanto en esa representación interior como en el exterior constitutivo. ${ }^{27}$

\section{La temporalidad}

En razón de la matriz teórica que planteamos y en atención a la configuración socio histórica de los ASC, se considera necesario incluir la dimensión temporal. Una temporalidad transversal y multiposicional. ¿En relación con cuáles indicadores vinculamos la temporalidad?

En primer lugar, la temporalidad del ASC. De acuerdo con esta dimensión se puede describir la trayectoria del ASC, su momento constitutivo, las readaptaciones internas, puede indicarnos curvas evolutivas y variantes que se van describiendo a lo largo de su perfil organizativo.

En segundo término la temporalidad de la experiencia de acción. Ambas son indisociables ya que al inicio se afirmó que es la segunda el clivaje central e identitario del actor. Permite seguir los repertorios de la acción que pueden iniciarse bajo un determinado repertorio y modificarse en su devenir o combinarse con otros.

En tercer lugar, la temporalidad de la construcción identitaria que permite marcar los cambios y variaciones en los componentes posicionales y representativos.

Finalmente, la temporalidad de las prácticas colectivas en el espacio social que permite apreciar cambios y continuidades en el devenir de las acciones colectivas.

\section{A modo de conclusión}

Un recorrido por el actual panorama de movilización social que acontece en América latina nos interpela acerca de los propósitos de las acciones colectivas protestatarias, ciertamente; pero ante todo nos coloca frente a actores sociales colectivos y, por lo tanto, confirma la oportuna tarea de revisitar tal categoría y repensar dimensiones de análisis que sean conducentes a estudiarlos e interpretarlos en sus espacios y temporalidades. Esta ha

\footnotetext{
${ }^{27}$ Estos indicadores pertenecen a los resultados de nuestro Proyecto de investigación en curso: Mapeo de actores colectivos, financiado por CONICET.
} 
sido la preocupación que dio inicio al interés por el tema.

A partir del momento en que las teorías sociológicas emprenden el rescate del actor y del sujeto, en el marco también del declive del marxismo y de las teorías estructuralistas, se amplifica el interés por los ASC desde giros epistemológicos renovados y perspectivas de análisis alternativas. Este trabajo recoge, en buena medida, algunas contribuciones relevantes en tal sentido para luego fundamentar una propuesta de abordaje teórico que se preocupa por la configuración socio histórica de ASC.

La historia social, la teoría social, la teoría del discurso político y la geografía han sido las fuentes teóricas que permitieron repensar la categoría en estudio y validar las dimensiones de análisis. Pero, nada de esta operación intelectual hubiera sido posible sin antes recuperar los resultados de las propias investigaciones relacionadas con actores colectivos. Precisamente, este aporte subraya la importancia que cobran los estudios descriptivos y fácticos, por cuanto conllevan interpelar las categorías iniciales de trabajo, complementarlas o profundizarlas en tal caso.

Propongo una definición sobre actor colectivo que centra en su configuración socio histórica; por lo tanto enfatiza en una dinámica relacional y en su proceso constitutivo. Es así como se recupera el valor explicativo de dimensiones macrosociales como el contexto, y de las dimensiones situadas -territorialidades y temporalidades- en que se desenvuelve una experiencia de acción colectiva, atravesada por su propia temporalidad pero con capacidad potencial de incidir en el contexto de referencia y en la reconfiguración del propio ASC.

Así entendemos que en la noción de ASC puede quedar comprendido individuos con pertenencia a un colectivo, situado en tiempo y articulador del espacio social, cuyo proceso constitutivo se inscribe en una matriz contextual e identitaria, mientras la configuración de una acción (más o menos contenciosa, con mayor o menor incidencia en el contexto) lo posiciona y visibiliza en el espacio público. Se trata de una definición provisoria y factible de contrastaciones e interpelaciones por otros marcos teóricos disciplinares así como por otras evidencias empíricas.

Situar al actor en relación con el contexto, en un tiempo histórico, en una escala, en el espacio público, desenvolviendo acciones colectivas puede conducirnos a entender mejor no solo actores, sociedades y tiempos sino percibir continuidades y rupturas, en las que pocas veces se repara y, sin embargo, son las que encierran claves interesantes para devolver a la historia el sentido explicativo del pasado y del presente.

\section{Referencias}

AGUIRRE ROJAS, C. A. (2010). Movimientos antisistémicos: pensar lo antisistémico en los inicios del siglo XXI. Rosario, Argentina: Prohistoria Ediciones, 2010.

ALBETI MAS, A.; BENACH, N. Doreen Massey. Madrid: Icaria, 2012. 
ALGUACIL GÓMEZ, J. Nuevos movimientos sociales: nuevas perspectivas, nuevas experiencias, nuevos desafíos, 2007. Disponible en: http://www.redalyc.org/articulo.oa?id=30501713 Consultado: 2 abril. 2019.

ARFUCH, L. Identidades, sujetos y subjetividades. Buenos Aires: Prometeo Libros, 2002.

ARDITI, B. El reverso de la diferencia. In: ARDITI, B. (edit). El reverso de la diferencia. Identidad y política. Venezuela: Nueva Sociedad, 2000. p. 99-124.

ARDITI, B. (2009). La política en los bordes del liberalismo. Diferencia, populismo, revolución, emancipación, $2009 . \quad$ Disponible en: https://arditiesp.files.wordpress.com/2017/01/arditi politicas en los bordes doble 2017.p df. Consultado: 10 mayo, 2019.

ASCOLANI, A. El sindicalismo rural en la Argentina. De la resistencia clasista a la comunidad organizada (1928-1952). Bernal: Universidad Nacional de Quilmes, 2009.

AUYERO, J. La protesta. Retratos de la beligerancia popular en la Argentina democrática. Buenos Aires: Ediciones Libros del Rojas, 2002.

BASCONZUELO, C. Actores sociales colectivos desde la historia social. Cultura en red. Río Cuarto: UniRío, 2019. p. 20-45.

BURKE, P.; DARNTON, R., GASKELL, I.; LEVI, G. [et al.]. Formas de hacer historia. Barcelona: Alianza Editorial, 1996.

BURKE, P. Historia y teoría social. Buenos Aires: Amorrortu editores, 2007.

CAÍNZOS LÓPEZ, M. Clases, intereses y actores sociales: un debate posmarxista, 1989. Disponible en: https://dialnet.unirioja.es/descarga/articulo/249415.pdf. Consultado: 21 marzo 2019. https://doi.org/10.2307/40183394

CASTELLS, M. La era de la información. Economía, sociedad y cultural. El poder de la identidad. Vol. II. México: Siglo XXI editores, 1999.

COENEN-HUTHER, J. Analyse de réseaux et sociologie générale, 1993. Disponible en: https://www.persee.fr/doc/flux 1154-2721 1993 num 913 962. Consultado: 19 setiembre, 2019. https://doi.org/10.3406/flux.1993.962

CROZIER, M. y FRIEDBERG, E. El actor y el sistema, 1977. Disponible en: www.arianesud.com > content > download > CROZIE...Consultado: 20 marzo. 2019

DUBAR, C. Y TRIPIER, P. (1998). Sociologie des professions, 1998. Disponible en: https://www.persee.fr/doc/genre 1298-6046 1999 num $26 \quad 1 \quad 1109$ t1 015700001

Consultado: 20 marzo 2019.

DUSELL, E. Sobre el sujeto y la intersubjetividad: el agente histórico como actor en los movimientos sociales, $1999 . \quad$ Disponible en: http://www.ceapedi.com.ar/imagenes/biblioteca/libreria/104.pdf Consultado: 28 abril, 2019.

EDER, K. Au-delà du sujet historique: vers une construction théorique des acteurs collectifs. L'Homme et la société., 1991. Disponible en: https://www.persee.fr/doc/homso 001843061991 num 1013 2565. Consultado: 12019. https://doi.org/10.3406/homso.1991.2565

ELÍAS, N. Trop tard ou trop tôt. Notes sur la classification de la théorie du processus et de la 
configuration. Norbert Elias par lui-même, traduit de l'allemand par Jean-Claude Capèle. Paris: Éditions Fayard, 1991.

ELIAS DE CASTRO, I. O problema da escala. In: ELÍAS DE CASTRO, I.; DA COSTA GOMES, P.; LOBATO CORRÊA, Geografía: conceitos e temas. Rio de Janeiro: Bertrand, 2000. p. 117-140.

FERNÁNDEZ, V.; BRANDÃO, C. Escalas y políticas del desarrollo regional: desafíos para América latina. Madrid: España, Miño y Dávila, 2010.

FERNANDES, B. Movimentos socioterritoriais e movimentos socioespaciais: contribuição teórica para uma leitura geográfica dos movimentos sociais, 2005. Disponible en: http://revista.fct.unesp.br/index.php/nera/article/view/1460/1436 Consultado: 2 setiembre, 2019.

GARCÍA SÁNCHEZ, E. El concepto de actor. Reflexiones y propuestas para la ciencia política, 2007. Disponible en: https://www.redalyc.org/articulo.oa?id=62830608. Consultado: 12 febrero. 2019.

GARCÍA GONZÁLEZ, G. (2017). Entre la historia y la sociología. Enfoques constructivistas en el estudio de los nuevos movimientos sociales, 2017. Disponible en https://www.jstor.org/stable/44509488? seq=1\#metadata info tab contents. Consultado: 12 abril, 2019.

GIARRACCA, N. Acciones colectivas y organización cooperativa. Reflexiones y estudios de caso. Buenos Aires: CEAL, 1994.

GIARRACCA, N. Estudios rurales y movimientos sociales: miradas desde el sur. Buenos Aires: CLACSO, 2017.

HALL, S. Introducción: ¿quién necesita identidad? In: HALL, S.; DU GAY, P. (comps.). Cuestiones de identidad cultural. Buenos Aires: Amorrortu editores, 1996. p. 13-39.

HERRERA GÓMEZ, M. La teoría relacional de la sociedad, 2001. Disponible en: http://revintsociologia.revistas.csic.es/index.php/revintsociologia/article/view/741

Consultado: 2 setiembre, 2019.

IBAÑEZ, J. El regreso del sujeto. La investigación social de segundo orden. Santiago de Chile: Editorial Amerinda, 1991.

IGLESIAS, E. Política y protesta. Visiones comparadas sobre la acción colectiva. In: FERNÁNDEZ, A.; LESGART, Cecilia (comps). La democracia en América Latina. Partidos políticos y movimientos sociales. Buenos Aires: Homo Sapiens, 2007. p. 157-172.

IMÍZCOZ BEUNZA, J.M. Actores y redes sociales en historia. In: CARVAJAL DE LA VEGA, D. ANÍBARRO RODRIGUEZ, J.; VÍTORES CASADO, I. (comps). Redes sociales y económicas en el mundo bajomedieval. Valladolid: Castilla Ediciones, 2011. p. 21-33. https://doi.org/10.5565/rev/redes.419

KOSELLECK, R. Futuro pasado. Para una semántica de los tiempos históricos. Barcelona: Paidós, 1993.

LACLAU, E. y MOUFFE, Ch. Posición de sujeto y antagonismo: la plenitud imposible. In: ARDITI, B. (edit). El reverso de la diferencia. Identidad y política. Venezuela: Nueva Sociedad, 2000. p. 153-167.

LAZEGA, E. Analyse de réseaux et sociologie des organisations, 1994. Disponible en: 
https://www.persee.fr/doc/rfsoc 0035-2969 1994 num 3524327 Consultado: 13 mayo, 2019. https://doi.org/10.2307/3322036

LEZAUN, J. La teoría del actor-red. In: BENZECRY, C.; KRAUSE, M.; ARIAIL REED, I. (edit.) La teoría social, ahora. Buenos Aires: Siglo Veintiuno Editores, 2019. p. 349-384.

LOPES DE SOUZA, M. Os conceitos fundamentais da pesquisa socio-espacial. Rio de Janeiro: Bertrand Brasil, 2013.

MOREYRA, B. El revival de la historia social en la primera década del siglo XXI: ¿̇etorno o reconfiguración? História da Historiografia, 2014. https://doi.org/10.15848/hh.v0i15.740

NARDACCHIONE, G. La acción colectiva de protesta: del antagonismo al espacio público. In: SCHUSTER, F.; NAISHTAT, F.; NARDACCHIONE, G.; PEREYRA, S., Tomar la palabra. Estudios sobre protesta social y acción colectiva en la Argentina contemporánea, 2005, p. 85-109. Buenos Aires: Instituto de Investigaciones Gino Germani.

NAVARRETE-CAZALES, Z. ¿Otra vez la identidad? Un concepto necesario pero imposible, Revista Mexicana de Investigación Educativa, v. 20, n. 65, p. 461-479, 2015.

NEVEU, E. Sociología de los movimientos sociales. Quito: Ediciones ABYA-YALA, 2000.

PORTO-GONÇALVES, C. A geograficidade do social: uma contribuição para o debate metodológico sobre estudos de conflito e movimentos sociais na América Latina, 2003.

POZAS, M. A. En busca del actor en la teoría del actor red. In: TONKONOFF, S. (Editor). Pensar lo social. Pluralismo teórico en América Latina. Buenos Aires: Clacso, 2018. p. 207-223.

SANTOS, M. A Natureza do Espaço. São Paulo: Editora Hucitec, 1996.

SCHERER-WARREN, I. Das mobilizações as redes de movimentos sociais. Soc. estado., v. 21, n. 1, p. 109-130, 2006. https://doi.org/10.1590/S0102-69922006000100007

SCHUSTER, F., NAISHTAT, F., NARDACCHIONE, G. Y PEREYRA, S. Tomar la palabra. Estudios sobre protesta social y acción colectiva en la Argentina contemporánea. Buenos Aires: Instituto de Investigaciones Gino Germani, 2005.

SEWELL, W. Por una reformulación de lo social. Ayer, v. 62, n. 2, p. 51-72, 2006.

SOUZA COELHO NETO, A. A espacialidade das ações coletivas: notas para o debate. In: MOREIRA CARNEIRO SANTOS, E., SOUZA COELHO NETO, A. y ARAUJO DA SILVA, O. (orgs.) Espacialidade e movimentos sociais. Salvador da Bahia: Consequência, 2018. p. 155-170.

SPIEGEL, G. La historia de la práctica: nuevas tendencias en historia tras el giro lingüístico, Ayer, v. 62, n. 2, 19-50, 2006.

SVAMPA, M. Movimientos sociales y nuevo escenario regional: Las inflexiones del paradigma neoliberal en América Latina, 2006. Disponible en https://www.sociohistorica.fahce.unlp.edu.ar/article/view/SHn19-20a06 Consultado: 10 octubre, 2019.

TARRÉS, M. L. Perspectivas analíticas en la sociología de la acción colectiva, Estudios sociológicos, v. 10, n. 30, p. 735-757, 1992.

TARROW, S. El poder en movimiento: los movimientos sociales, la acción colectiva y la política. Barcelona: Alianza, 1998.

THÉVENOT, L. La acción en plural. Una introducción a la sociología pragmática. Buenos Aires: 
Siglo Veintiuno Editores, 2016.

TILLY, Ch. Acción colectiva, 1995. Disponible en:

https://es.scribd.com/doc/59967244/Tilly-Charles-Accion-colectiva Consultado: 20 octubre, 2019.

TOURAINE, A. El regreso del actor. Buenos Aires: Eudeba, 1987.

TOURAINE, A. Un nouveau paradigme. Pour comprendre le monde d'aujourd'hui. Paris: Fayard, 2005.

TOURAINE, A. Sociología: De los sistemas a los actores, 2006. Disponible en: https://es.scribd.com/document/261969504/Sociologia-de-Los-Sistemas-a-Los-Actores

Consultado: 22 marzo, 2019.

TRAUGOTT, M. Protesta social. Repertorios y ciclos de la acción colectiva. Madrid: Hacer Editorial, 2003.

VALENCIA, G. Entre cronos y kairos. Las formas elementales del tiempo socio histórico. Barcelona: Anthropos, 2008.

VILAS, C. Actores, sujetos, movimientos: ¿Dónde quedaron las clases? Sociológica, v. 10, n. 28, p. 1-22, 1995.

WAGNON, C. B. G. Por una sociología relacional, 2013.

Recebido em: 05/11/2019.

Aceito em: 16/02/2020. 